\title{
0 desenvolvimento tecnológico e o pequeno produtor rural: construção, desconstrução ou manutenção da sua identidade?
}

\author{
Technological development and the small rural producers: construction, deconstruction \\ or maintenance of their identities?
}

Luciano Mendes ${ }^{1}$

Elisa Yoshie Ichikawa²

\section{Resumo}

0 objetivo deste artigo é compreender a influência do programa de desenvolvimento tecnológico denominado Arenito Nova Fronteira no processo de construção, desconstrução ou manutenção da identidade do pequeno produtor rural da região de Umuarama (PR). Para tanto, foi realizado um estudo sobre a identidade, na perspectiva de vários autores, transitando nos contextos filosófico, sociológico e psicológico, com a intenção de extrair os pressupostos que guiam esses campos. Assim, a técnica de entrevista utilizada seguiu a temática da história de vida, pois a identidade toca em aspectos como a continuidade do sujeito no contexto social. Com esse arcabouço teórico e metodológico foram entrevistados cinco pequenos produtores rurais de Umuarama, para que falassem de suas histórias de vida. Os resultados mostram que, após a implantação do programa Arenito Nova Fronteira na região, esses pequenos produtores entraram num processo de desconstrução de suas identidades, pelo fato do programa não ter atendido aos seus anseios e necessidades.

Palavras-chave: identidade; pequeno produtor rural; desenvolvimento tecnológico; Programa Arenito Nova Fronteira.

\section{Abstract}

The objective of this paper is to understand the influence of the technological development program called "Arenito Nova Fronteira" on the process of construction, destruction or maintenance of the identity of the small rural producers in the area of Umuarama-PR. Therefore, a study about identity was developed based on several perspectives, including the philosophical, sociological and psychological contexts, with the intention of extracting the presuppositions that guide those fields. Thus, the interview technique implemented in this work followed the thematic of life history, because identity touches aspects such as the subject's continuity in the social context. Based on this theoretical and methodological basis, five small rural producers from the area of Umuarama were interviewed with the objective of talking about their life's histories. The results show that, after the implementation of the program in the region, the small rural producers entered in a process of deconstruction of their identities, due to the fact that the program didn't assist them with their aspirations and needs.

Key words: identity; small rural producer; technological development; Arenito Nova Fronteira Program.

\footnotetext{
${ }^{1}$ Doutorando em Administração pela Universidade Federal do Rio Grande do Sul/UFRGS. Professor da Universidade Federal de Mato Grosso do Sul (UFMS). Endereço: Rua 44, n. 776. Jardim Alvorada. Barretos/São Paulo - Brasil - CEP. 14780-190. E-mail: lucianobtos@yahoo.com.br

${ }^{2}$ Doutorado em Engenharia de Produção pela Universidade Federal de Santa Catarina/UFSC. Professora da Universidade Estadual de Maringá (UEM). Endereço:Avenida Colombo, 5790 - UEM/CSA/DAD. - Maringá/Paraná - Brasil - CEP 87020-900. E-mail: elisa@wnet.com.br.
} 


\section{Introdução}

O desenvolvimento da agricultura brasileira foi extremamente importante para sustentar o processo de modernização em que o país ingressou. Com a formação de um parque industrial, a partir do século XX, a necessidade de sustentá-lo tornou-se vital, o que só foi possível quando a agricultura - de onde provém os principais insumos utilizados no processo industrial - também se modernizou. Como em todos os países capitalistas do Ocidente, o Estado teve um papel central no processo de modernização da sociedade brasileira, realizando inúmeras intervenções que garantissem o sucesso das iniciativas pelo desenvolvimento.

Essa intervenção estatal ganha destaque na agropecuária brasileira, principalmente, a partir da década de 1930, com o desfalque nas exportações de café, quando o governo brasileiro elaborou uma política de substituição de importações, via estímulo à industrialização interna (FURTADO, 1963). Com a tendência crescente à urbanização e o contínuo crescimento dos sistemas industriais e de serviços - gerando uma demanda elevada por alimentos -, logo foram desencadeadas algumas crises no abastecimento dos grandes centros. Nesse contexto, visualizando o problema da falta de alimentos é que o governo se volta mais intensamente para a pesquisa e a extensão rural no país.

Não há como negar, entretanto, que nesse contexto de investimento no desenvolvimento, o Estado sempre privilegiou aquelas categorias - principalmente, na agricultura - que mais pudessem contribuir, de imediato, para salvaguardar o país das crises pelas quais este passou. Com isso, na concepção de Carvalho (1992), fica fácil concluir que a pesquisa agrícola brasileira foi estimulada mais para atender às necessidades dos grandes produtores de culturas de exportação do que às necessidades ou aos interesses de pequenos e médios produtores de culturas alimentares e seus consumidores.

Somente mais tarde, com o desenvolvimento tecnológico das grandes propriedades e com a constatação de que a pequena agricultura, em grande parte, era a responsável pelo abastecimento do mercado interno, é que se destinou atenção especial a este ramo de atividade. Nesse ínterim, já se tornara predominante no âmbito dos estudos sobre a propriedade rural, o entendimento de que a "agricultura modernizada" estava ligada aos complexos agroindustriais e a "agricultura tradicional" àquela praticada de forma rudimentar.

Fica fácil visualizar que as características da pequena agricultura se assentavam nos aspectos mais tradicionais, devido à marginalização, por parte do Estado, dos problemas desses pequenos produtores. Nesse contexto, com o desenvolvimento da grande propriedade rural - cujo foco eram os produtos de exportação - e visualizando a opressão do mercado sobre essa agricultura tradicional, é que o Estado, através dos institutos de pesquisa, voltou-se mais intensamente para o problema da pequena propriedade rural. A intenção era "modernizar" a pequena propriedade, possibilitando-lhe concorrer no mercado interno, o que dirimia, em grande parte, a exclusão e a pauperização desses pequenos produtores.

Esse processo de modernização da pequena agricultura sempre foi um dos problemas centrais nos estudos da área de sociologia rural, pois o impacto da mudança, num curto espaço de tempo, de uma agricultura tradicional para uma agricultura modernizada, refletia muito da resistência de vários pequenos produtores às mudanças propostas. Nesse contexto, vários autores, como Freire (1977), constatando a ineficácia do processo de transferência de tecnologia aos pequenos produtores, discutiam formas diferentes de realizar essa transferência, que até então era realizada nos pressupostos daquilo que Carvalho (1992) chamou de "modelo concentrado". O que guiava as iniciativas de desenvolvimento nessa concepção do modelo concentrado partia da constatação de que os produtores não possuíam visão crítica, muito menos capacidade de optar pela melhor tecnologia a ser adotada, por falta de conhecimentos.

Assim, modernizar a pequena propriedade se tornava um problema, devido às manifestações de resistência e pouca adotabilidade, pelos pequenos produtores, de novos métodos de produção e novas variedades de culturas mais adaptadas à sua região. As propostas sugeridas (principalmente, por sociólogos rurais) consideravam desde a questão da "ignorância" do pequeno produtor sobre as novas tecnologias até a questão do "desinteresse" dos mesmos em adotar tais tecnologias, o que implicaria diferentes métodos de intervenção. 
O que se observa ainda hoje é uma resistência dos pequenos produtores a mudanças no processo de produção que desenvolveram ao longo de sua história de trabalho com a terra. Isso revela que a problemática do desenvolvimento da pequena propriedade vai além de fatores como "ignorância" ou "desinteresse". Na verdade, diz respeito a um tema pouco explorado pelos sociólogos rurais, que é a identidade do pequeno produtor. Portanto, ter um entendimento mais aprofundado dos fatores determinantes dessa resistência implica observar o processo de desenvolvimento rural a partir do impacto que este exerce na subjetividade desse pequeno produtor e de como tal subjetividade impacta esse processo. Como um dos componentes da complexa subjetividade do sujeito, a identidade possibilita a esse sujeito a sensação de continuidade no contexto social. É ela que lhe dá impressão de ser quem sempre foi, mesmo passando por várias mudanças durante sua história de vida. Além disso, a identidade está relacionada com a questão da diferença, pois é ela que particulariza os indivíduos, distinguindo-os no contexto social.

Assim, o objetivo deste artigo é compreender a influência de um programa governamental de desenvolvimento tecnológico, denominado Arenito Nova Fronteira, na identidade do pequeno produtor inserido no município de Umuarama (PR) onde ocorreu esse processo de desenvolvimento.

O programa Arenito Nova Fronteira foi implantado no noroeste do estado do Paraná, região que abriga mais de 107 municípios que sofrem de um mesmo problema: o alto teor de areia no solo. Isso inviabilizou, durante algum tempo, o plantio e a disseminação de cultivares nessa região, que teve como fonte principal de produção, nos últimos anos, a pecuária extensiva. Foi com a constatação desse problema que o Instituto Agronômico do Paraná (Iapar), na qualidade de órgão oficial da pesquisa agrícola no estado, desenvolveu um projeto para estabelecer ciclos de lavouras para a produção de grãos e forragens em alternância com ciclos de pastagens semiperenes de alta qualidade e produtividade, em benefício da produção animal e da melhoria do uso da terra. Uma de suas primeiras parcerias, nesse sentido, foi com a prefeitura de Umuarama, através do Programa de Arrendamento de Terras (Pater), o qual teve o respaldo do Iapar na difusão de novas tecnologias. Essa parceria teve grande impacto econômico e originou o programa governamental denominado Arenito Nova Fronteira, sendo este o contexto de estudo desta pesquisa.

\section{As discussões sobre identidade}

O termo identidade assume inúmeras conotações nos contextos filosófico, sociológico e psicológico. O crescente debate no âmbito das ciências humanas, apesar das semelhanças, acabou revelando a complexidade do termo. Se nas primeiras discussões, a identidade estava vinculada a algo "ossificado" na subjetividade do sujeito, nos dias atuais, ela circunscreve uma série de atributos, os quais possibilitam, mesmo com alterações radicais, que o sujeito seja ele mesmo, ou melhor, que tenha a percepção de ser quem sempre foi.

Na concepção de Souza Santos (1991), as discussões sobre a identidade nascem na modernidade, quando a constatação da subjetividade vai ser um dos indícios de sua existência. Assim, um dos primeiros campos a discutir a identidade é o filosófico, através do estudo de Hegel (2002), com a famosa conceituação de que a identidade funciona como a fórmula A=A. Essa fórmula, na análise de Hegel (2002), designa o absoluto, que é dado de imediato ao sujeito e que irá permear o vir-a-ser-de-si-mesmo, pois é esse absoluto que designa o fim a ser atingido pelo sujeito. O pensamento desse filósofo é complexo, o que não permite uma análise a fundo na curta empreitada deste artigo, mas algumas considerações são possíveis. Assim, para ele, o sujeito só consegue atingir esse absoluto numa relação dialética, negando a realidade que o oprime, pois só assim é possível ao sujeito se libertar de um sistema que limita suas manifestações.

É nesse ponto que Habermas (1990), ao fazer uma análise do pensamento de Hegel, diz que este foi um dos primeiros filósofos a constatar a bipartição da modernidade; isto é, a constatar a existência de um mundo subjetivo (coordenado pelo conhecimento) e de um mundo objetivo (formado pela realidade). Nesse cenário, Hegel (2002) acreditava que, apesar do processo dialético de interferência recíproca entre esses dois contextos, a partir do momento em que o sujeito interferia no conteúdo da realidade e se libertava desse conteúdo, ele deixava aflorar de forma mais definitiva sua identidade absoluta, pois a igualdade existente em $\mathrm{A}=\mathrm{A}$ só poderia prevalecer como oposto de não-A, pelo fato de que a identidade de A resulta da contradição e a contém. Marcuse (1978) comenta essa passagem do texto de Hegel dizendo que, nessa linha, a identidade do ser 
humano encontra-se naquelas relações que são a negação de sua particularidade isolada, na qualidade de membro de um grupo ou de uma classe social, cujas instituições, organizações e valores determinam sua própria individualidade.

Desse modo, vale salientar algumas contribuições de Hegel (2002) para este estudo, referente ao conceito de identidade. Antes de tudo, que a fórmula $\mathrm{A}=\mathrm{A}$ remete a algo como a continuidade do sujeito, ou até à possibilidade do sujeito deixar aflorar aquilo que ele realmente é, numa constante interferência no conteúdo da realidade. Além disso, a identidade vai congregar dois termos que, de início, parecem contraditórios: identidade e diferença. Acredita-se que dessa discussão sobre a ideia de Hegel, mesmo simplificada, afloram aspectos do próprio conceito de identidade que se tem hoje, isto é, a identidade vai estar ligada àquilo que possibilita ao indivíduo ser o que sempre foi, e também que ele seja único e individual nas suas relações sociais.

Anos mais tarde, é Heidegger (1971) que vai retomar esse pensamento de Hegel sobre a identidade e, apesar de não discordar do conceito ou característica da identidade formada na teoria hegeliana, esse autor vai dar outra conotação à forma como o indivíduo vai deixar aflorar sua verdadeira identidade. Assim, Heidegger (1971) inicia seu estudo dizendo que o princípio da identidade soa conforme a fórmula corrente: A=A. Essa fórmula, na concepção desse autor, exprime a igualdade entre dois termos; não a identidade. A palavra identidade tem como radical o termo latim idem, que Heidegger (1971) compara com a designação "tò autò" em grego, a qual significa "o mesmo". Assim, segundo esse autor, se alguém repete sem cessar o mesmo, acaba por exprimir uma tautologia, o que acontece no princípio $\mathrm{A}=\mathrm{A}$. Portanto, Heidegger acredita que a fórmula adequada para $\mathrm{o}$ princípio da identidade seria: A é A; querendo exprimir que cada A é ele mesmo.

Para explicar essa mudança na fórmula da identidade, Heidegger (1971, p.53) realiza uma análise do pensamento de Parmênides, para quem "o mesmo, pois, tanto é apreender (pensar) como também ser". Com esse resgate, Heidegger (1971) coloca duas coisas, até então distintas, num mesmo patamar: ser e pensar. Para esse autor, antes mesmo da identidade ser formulada, pensar e ser têm um lugar, formando juntos uma unidade. Essa união entre pensar e ser, Heidegger (1971) chamou de comum-pertencer.

Com essa designação comum-pertencer, Heidegger (1971) extrai dois sentidos. O primeiro, tentando mostrar o possível sentido hegeliano da identidade. Nesse ponto, faz uma síntese da discussão realizada anteriormente, pois na concepção de Hegel, a identidade se expressa entre ser e pensar, ser e homem (pois o homem é o único ser pensante), resultado de um progresso. Por sua vez, o segundo sentido mostra a identidade em sua perspectiva, pela qual aquela é a unidade de ser e homem, concebida através de um regresso.

Para Heidegger (1971), é indiscutível que, embora, a identidade se estabeleça na relação entre ser e homem, entre ser e pensar, ela não é constituída a partir de um progresso no âmbito da razão, como acreditava Hegel (2002), mas, sim, a partir de um regresso. Heidegger (1971) relata que a identidade se funde no distanciar da atitude do pensamento que representa, afastando-se da comum representação do homem como animal racional que na modernidade tornou-se sujeito para seus objetos. Nesse contexto, Heidegger (1971) não acredita, diferindo de Hegel (2002), que a razão seja o processo pelo qual o indivíduo busca sua verdadeira identidade, mas pelo qual a despersonifica quando se torna racional. Isso porque, salienta esse autor, homem e ser já se constituem numa unidade em sua essência, como a pedra, a árvore etc. Por esse motivo, acredita que o distanciar desse mundo onde o homem está reduzido a um ser do universo da técnica é a maneira mais evidente de vislumbrar a essência da identidade.

Essa discussão entre Hegel e Heidegger perpassa as considerações mais evidentes que se tem sobre a identidade nos dias atuais e vai contribuir para muitas discussões sobre essa temática, também, nos contextos psicológico e sociológico. Psicológico porque a identidade ainda continua sendo algo ligado ao contexto subjetivo, a que somente o indivíduo tem acesso. Sociológico porque a identidade, apesar das características individuais e subjetivas, constitui uma ligação evidente com um campo maior, pois grande parte da matéria-prima de onde é possível evidenciar a identidade provém das relações que o indivíduo estabelece no contexto social.

Como foi expresso no início, a identidade, apesar de suas características que permeiam as discussões atuais sobre esse termo - unicidade e continuidade do sujeito - era vista como algo "ossificado" na subjetividade, como a essência daquilo que é o sujeito. Foi assim também na psicanálise freudiana, que desvelou muitos dos 
atributos ligados ao inconsciente do ser humano, como algo na subjetividade do sujeito que determina sua conduta. Freud nunca escreveu nada sobre a identidade em si, mas em uma de suas conferências para a sociedade psicanalista, como mostra Erikson (1976), falou sobre o atributo de ser judeu, o que tentara negar durante toda sua vida, mas que sempre esteve presente, condicionando suas atitudes e ações, pois era um atributo ligado à sua identidade.

Apesar de nunca ter escrito nada sobre a identidade, Freud deixou muitas contribuições para entendermos seu funcionamento na subjetividade do sujeito. Assim, com suas discussões sobre as três instâncias do desenvolvimento mental - o id, o ego e o superego - e também com suas discussões sobre as pulsões de vida e de morte (ver sobre esses tópicos em FREUD, 1974, 1975, 1976b), Freud conseguiu mostrar que, apesar das mudanças que os indivíduos passam como membros de uma sociedade, algo continua determinando suas atitudes, ligado a esse contexto que ele chamou de inconsciente. Nesse ponto, Freud (1976a) falou de características presentes nos indivíduos que foram herdadas de seus ancestrais e que convivem com as características geradas e difundidas nas sociedades atuais. Essa conotação freudiana mostra que alguns atributos da identidade do indivíduo tendem a permanecer, mesmo que outros atributos sejam aceitos e alterados. Deve ser ressaltado que, apesar da evidência de que, nessa discussão sobre os resquícios ancestrais, a identidade está ligada a algo "ossificado", Freud revelou que esta incorpora atributos colhidos no contexto social, proporcionando constante mudança de alguns atributos do indivíduo ao longo de sua vida.

Essa ideia freudiana de mudança dos atributos vai alimentar uma série de discussões sobre a identidade nos dias atuais. Destinando menos atenção à discussão da identidade como algo "ossificado", Erikson (1976) vai trabalhar todo o ciclo de constituição da identidade do indivíduo, do nascimento à velhice, enfatizando a juventude, período em que o indivíduo sofre várias crises de identidade. Na concepção de Erikson (1976), o termo identidade, desde os primórdios de sua discussão, refere-se a um sentimento subjetivo de uma envigorante uniformidade e continuidade. Algo novo aparece nas considerações de Erikson (1976), pois ele concebe a identidade como um sentimento, que vai permitir entender, nos dias atuais, o que faz com que os sujeitos passem por várias mudanças durante sua vida e continuem com a impressão de que são o que sempre foram.

Assim, Erikson (1976), com uma aproximação da psicanálise freudiana, vai falar sobre sentimentos bons, os quais possibilitam aos indivíduos construírem sua identidade, considerando aquilo que o autor chama de reconhecimento mútuo entre sujeitos, confiança e entendimento, formador do que ele denomina de identidade positiva. Por outro lado, Erikson (1976), fala também dos sentimentos ruins, que vão alterar o conteúdo estabelecido no processo de construção da identidade, em que os sujeitos sofrem a chamada identidade negativa ou crise de identidade. Nesse contexto, ocorre o processo de desconstrução e reconstrução de uma "nova" identidade que vai permitir congregar ali os atributos modificados pela crise de identidade. Essa discussão tem, em nível do sujeito, uma leve aproximação com a dialética hegeliana (tese, antítese e síntese) - guardadas as considerações ideológicas sobre esse processo -, que a psicanálise vai chamar de sentimento de ambivalência; ou seja, ora o sujeito nega determinado atributo, ora aceita e afirma esse mesmo atributo - guardadas também as discussões psicopatológicas da ambivalência. Essa reflexão visa poder contemplar como o processo de construção e desconstrução da identidade perpassa, sem muitos entraves, discussões há muito difundidas nos contextos filosófico e psicológico.

Entretanto, as considerações sobre a identidade não se limitam apenas aos contextos filosófico e psicológico. Estendem-se para um contexto sociológico que muito responde sobre a questão da continuidade e da individualidade contida na identidade. Da mesma forma, permite evidenciar e ampliar tanto as discussões iniciadas por Hegel e Heidegger quanto aquelas levantadas por Freud e Erikson. Como Erikson (1976) mesmo expõe no seu estudo, pelo fato da identidade se estabelecer também no núcleo central da cultura na qual o indivíduo está inserido, é necessário ampliar e transcender essas discussões para o contexto social, com a intenção de intensificar e entender muitos atributos ligados à questão da identidade.

Nesse contexto sociológico, devido ao fato dos debates sobre a identidade serem recentes - em comparação com as perspectivas psicológica e filosófica -, os conceitos e discussões vão tomar uma característica mais fluida e fragmentária, por causa da interferência da cultura. Aqui, a identidade é vista não simplesmente como 
uma identidade individual ou psicológica, mas como uma identidade cultural e até mesmo social. É isso que está expresso no conceito de identidade exposto por Souza Santos (1991), que a observa como "identificações em curso". Apesar desse termo "identificação" ser proveniente de um contexto psicológico, Souza Santos (1991) utiliza-o em nível simbólico de atribuições de significados dos atributos culturais. Assim, se a identidade está simplesmente ligada a um atributo cultural, qualquer modificação nesse atributo causa uma modificação na identidade. Por esse motivo, Souza Santos (1991) afirma que mesmo as identidades que parecem mais "sólidas" - como, por exemplo, homem ou mulher -, são passíveis de serem modificadas.

Apesar de atual e instigante essa discussão promovida por Souza Santos (1991), para outros autores, como, por exemplo, Touraine (1995), as identidades, mesmo observadas por esse contexto cultural, são passíveis de resistirem às mudanças, tentando permanecer como sempre foram. Isso mostra que as sociedades em si não estão entregues a um processo constante de mudanças, promovido através da racionalização, mas que resistências afloram do sujeito quando este se defronta com situações de mudanças extremas.

Além dessas considerações expostas por Touraine (1995), outra vertente a ser analisada sobre essa questão da resistência e as mudanças processadas no contexto sociocultural pode ser extraída dos estudos de Giddens (1991, 2002) e de Domingues (2001). Para esses autores, a modernidade é vista pelo que eles chamam de "mecanismo de desencaixe", pelo qual o sujeito já tem uma identidade dada e construída e as mudanças sociais retiram esses sujeitos desse contexto, implantando ali maior mobilidade e fluidez em suas vidas.

São essas conotações que fizeram com que Castells (1999) discutisse três formas originais de construção da identidade:

1. a entidade legitimadora: adotada pelas instituições dominantes, com o intuito de se legitimarem, expandindo e racionalizando sua dominação;

2. a identidade de resistência: criada por atores que se encontram em posições ou condições desvalorizadas; e

3. a identidade de projeto: quando os atores constroem uma nova identidade capaz de redefinir sua posição na sociedade. Somente nesse último caso, relata Castells, o indivíduo passa a ser sujeito, como ator, pois é ele quem projeta e muda sua vida.

Nesse contexto de discussão, a identidade passa a ser vista como identidade cultural e, até mesmo, social. Na conjuntura da psicologia, como é possível observar no trabalho de Erikson (1976), ela passa a ser vista como uma identidade psicossocial. Apesar dessa constatação, a identidade continua sendo algo que individualiza o sujeito, pois faz parte de um processo de construção em que este é ator nessa trama.

Para concluir esse raciocínio, vale salientar que essa discussão desmistifica alguns pressupostos encontrados no trabalho de Hegel (2002) e também no de Heidegger (1971), como a questão da identidade como algo ligado à essência do ser humano ou, mesmo, como algo "ossificado". No entanto, deve igualmente ser ressaltado que só a partir das discussões geradas por esses intelectuais é que se pôde entender a complexidade ligada ao termo identidade nos dias atuais. Embora os trabalhos de Heidegger (1971) e de Hegel (2002) sejam, até certo ponto, projetos pouco visíveis nos dias atuais, suas contribuições são inúmeras, pois foram eles que permitiram observar a identidade como qualificação do ser, como algo que torna os homens diferentes uns dos outros, que permite ao indivíduo ter a impressão de ser o que sempre foi, mesmo passando por mudanças radicais. São essas ideias discutidas até aqui que permitiram analisar em que momentos houve o processo de construção, de desconstrução e até de manutenção da identidade dos pequenos produtores entrevistados. Para tanto, é necessário retomar as discussões sobre o desenvolvimento tecnológico na agricultura, como forma de verificar de que modo as mudanças tecnológicas podem impactar na identidade do pequeno produtor rural.

\section{0 desenvolvimento tecnológico na agricultura}

Diante das discussões sobre o desenvolvimento da agricultura brasileira, Carvalho (1992) relata que o Estado foi o grande financiador desse desenvolvimento, através da constituição de vários institutos de pesquisa e de escolas de agronomia, visando impulsionar o avanço da ciência e da tecnologia no setor. 
Carvalho (1992) comenta que, a partir da década de 1940, o Ministério da Agricultura promoveu a criação de vários institutos, em regiões estratégicas, que tinham o objetivo de pesquisar culturas regionais, realizar o melhoramento tecnológico, bem como adaptar variedades de culturas melhoradas às diversas regiões do país. A partir da década de 1960, relata esse autor, houve a valorização do uso de defensivos agrícolas, devido à instalação das indústrias de insumos modernos. Além desse fato, as investigações também foram direcionadas para estimular os processos de estruturação do complexo agroindustrial do país. Com isso, autores como Carvalho (1992) e Ichikawa (2000) expõem que as organizações estatais de P\&D agrícola contribuíram, de alguma forma, para o dinamismo desse modelo de desenvolvimento. Isto é, o Estado acabou sendo uma figura central na ligação entre os subsistemas agropecuários e os demais subsistemas industriais e comerciais.

Nesse contexto, Carvalho (1992) acrescenta que também a partir da década de 1960, a preocupação dos pesquisadores, em coerência com as políticas desenvolvimentistas do país, passou a ser a de tornar a terra produtiva. $\mathrm{O}$ autor mostra que essa ênfase se deve às crises de abastecimento ocorridas até então, que acabaram resultando na criação da Empresa Brasileira de Pesquisa Agropecuária (Embrapa).

O modelo institucional que fundamentou a criação da Embrapa, na visão de Carvalho (1992), pautou-se por duas diretrizes. Primeiro, uma ação coordenadora, programática e normativa das pesquisas, que seriam realizadas por empresas estatais ou programas integrados. Segundo, uma atuação por produtos, condicionadas por centros nacionais e regionais de recursos, além de unidades de pesquisas no âmbito estadual. Para esse autor, o modelo preconizado pela Embrapa foi o chamado "modelo concentrado", pois

Partiu-se do pressuposto de que o país não dispunha de recursos financeiros em abundância, de massa crítica de pesquisadores e de massa crítica de empresários que se dirigissem aos institutos e formulassem, eles próprios, os seus sistemas de produção. A alternativa seria, portanto, dirigir as pesquisas para determinadas atividades e produtos, de modo a viabilizar a montagem de sistemas de produção para oferecer aos agricultores e pecuaristas. (CARVALHO, 1992, p.129)

Esse autor comenta que cabia aos centros de pesquisa desenvolver novas tecnologias - como o uso de máquinas e insumos agrícolas e de sementes melhoradas geneticamente, entre outras -, além de gerar soluções para os problemas existentes, com a intenção de difundi-las entre os produtores. Aqui, é possível ressaltar dois aspectos: primeiro, a importância da extensão rural nesse contexto de difusão de tecnologia; segundo, o que o próprio Carvalho (1992) apresenta sobre a pesquisa agrícola, de ter sido estimulada para atender às necessidades dos grandes produtores, em detrimento das necessidades e interesses dos pequenos e médios. Carvalho (1992) comenta que a intenção da extensão rural sempre foi proporcionar a difusão de informações e tecnologias aos produtores rurais, visando ao aumento da produtividade. Esse modelo de extensão rural, originário das experiências norte-americanas, comenta esse autor, teve um papel central na difusão das chamadas novas tecnologias no campo.

Ante essa discussão, e retomando as considerações de Carvalho (1992) e de Ichikawa (2000), sobre a ênfase dos institutos de pesquisa na difusão de tecnologias aos grandes produtores, bem como sobre a homogeneização de culturas em determinadas regiões, cabe aqui uma discussão um pouco mais aprofundada sobre esse papel atribuído à extensão rural.

Freire (1977) abre uma discussão sobre a extensão rural como invasora cultural. Para esse autor, no termo "extensão" está implícita a ação de levar, transferir, depositar algo em alguém; prática comum no processo de educação. Segundo ele, no âmbito da extensão rural, existe a conotação de que o conhecimento do mundo é algo que deve ser transferido e depositado no educando. Conotação essa que, segundo Freire (1977), rompe com a verdadeira natureza do conhecimento, que requer curiosidade do sujeito, exigindo deste que seja ator do processo e não, objeto. Assim, Freire (1977, p.36) expõe que "o conhecimento não se estende do que se julga sabedor até aqueles que se julga não saberem; o conhecimento se constitui na relação homem-mundo, relações de transformação, e se aperfeiçoa na problematização crítica destas relações".

Para esse autor, a ação do homem sobre o mundo não constitui apenas uma ação sobre a natureza, mas também uma ação social, porque o homem é também cultura e história. Assim, Freire (1977) ressalta que o invasor reduz os homens do espaço social invadido a meros objetivos de sua ação, infundindo seus sistemas de valores 
no espaço histórico-cultural destes. Aqui, vale retomar as discussões sobre identidade, pois uma ação que altere esse conteúdo histórico e cultural também altera a identidade do sujeito. Tal ação será construção ou desconstrução da identidade, dependendo de como essa alteração foi realizada; no caso deste artigo, dependendo de como se deu o desenvolvimento tecnológico numa região. Portanto, Freire (1977) acredita na possibilidade de realizar a "extensão" rural de modo que o extensionista não invada o mundo cultural do produtor, mas realize a "extensão" de forma dialógica.

Freire (1977) leva suas considerações para o limiar da problemática do processo de desenvolvimento rural: o pequeno produtor. Isso porque, expõe o autor, esse tipo de exploração agrícola se assenta, em grande parte, sobre métodos "rudimentares" de trabalho com a terra. Essa constatação, coloca Freire (1977), leva vários extensionistas a uma atitude de descrença quanto ao modo de agir do pequeno produtor; pois acabam subestimando não apenas o poder dos pequenos produtores de refletir, mas também a capacidade destes de assumir o papel de quem procura conhecer. Esse, talvez, tenha sido o grande pressuposto do chamado "modelo concentrado" de pesquisa agrícola da Embrapa, exposto por Carvalho (1992) no início desta seção.

Essa problemática não expressa a realidade da agricultura de subsistência, pois esse modelo de desenvolvimento tecnológico pouco influiria nessas comunidades. Além disso, muitos autores, como Castro et al (1979), acreditam que a agricultura de subsistência está quase em extinção em algumas regiões do país, como a Sudeste e a Sul. Nesse contexto, Alves (1988) mostra que a pequena propriedade rural acaba concorrendo com médios e grandes produtores que se modernizaram. Para esse autor, seria necessário que o Estado viabilizasse a modernização dessa pequena propriedade, fazendo repercutir aqui, novamente, a discussão de Freire (1977) sobre como realizar essa modernização.

Nessa mesma linha, Alencar (1997) ressalta que para autores como Kitching, Sardan e Brown, nem mesmo as estratégias pautadas na organização dos produtores, na participação e na geração de novas tecnologias apropriadas são suficientes para eliminar a tendência de exclusão e pauperização da pequena propriedade rural. Apesar desse panorama de total desarticulação dos pequenos produtores rurais, Alencar (1997) mostra que a maneira como a intervenção ocorre - que está na base também do pensamento de Freire (1977) -, não no sentido simplesmente de "injetar" mais conhecimento, mas de proporcionar a organização dos pequenos produtores e a geração de tecnologias apropriadas, pode ser um fator essencial para aumentar o seu poder de contraposição.

Nesse contexto, Ammann (1980) expõe que esses instrumentos podem não provocar a pretendida mudança social, se forem efetivados de maneira isolada, tais como a educação, a organização ou o desenvolvimento de comunidades. Apesar dessas considerações, Alencar (1997) coloca que as discussões sobre o desenvolvimento da agricultura geram questões fundamentais, que podem assumir características de "questões agrícolas" (onde produzir, o que produzir, quando produzir etc.) e de "questões agrárias" (como se produz, de que forma se produz etc.). Para esse autor, a resposta a determinadas questões decorrerá do modo como os diferentes atores sociais interpretem esse cenário, identificando problemas, suas causas e propondo estratégias, bem como dos recursos de poder de que dispõem para implementá-las.

Ampliando e complexificando essa temática exposta por Alencar (1997), Accarini (1987) apresenta as diversas temáticas em que os estudos sobre o desenvolvimento rural podem estar assentados, que compreendem, por exemplo, as técnicas e fatores de produção empregados, o grau de integração nos mercados internos ou externos, a rentabilidade e o uso ou destino dos produtos gerados. A partir da verificação dessas conotações, a agricultura pode ser caracterizada como tradicional ou moderna, de subsistência ou comercial, destinada ao mercado interno ou ao externo e, ainda, de baixa ou de alta rentabilidade. Com essa discussão, Accarini (1987) reafirma a complexidade que a agricultura brasileira adquiriu com o processo de modernização e integração ao mercado.

É devido a essas discussões sobre como o processo de desenvolvimento tecnológico vem se dando no contexto da agricultura brasileira e a respeito da marginalização dos próprios produtores do processo de desenvolvimento tecnológico que este artigo se efetiva. Isso decorre do fato de que as discussões sobre desenvolvimento tecnológico na agricultura marginalizam os reais problemas enfrentados pelos pequenos 
produtores, o que instigou verificar essa dinâmica na perspectiva deles. Essas considerações serão desenvolvidas na próxima seção.

\section{Percurso metodológico da investigação}

A pesquisa aqui proposta foi realizada com cinco pequenos produtores rurais da região de Umuarama (PR), com o intuito de verificar o impacto das ações de um programa governamental de desenvolvimento tecnológico, denominado Arenito Nova Fronteira, em sua identidade. Vale salientar que para fins de caracterização, foi denominado, de forma fictícia, o nome desses pequenos produtores como Joaquim, Pedro, Avelino, José e Sebastião, durante a apresentação dos dados.

Tendo como foco de investigação a identidade do pequeno produtor, a pesquisa desenvolvida se aproxima de uma pesquisa de cunho qualitativo, pois como diz Minayo (1996), quando se procura apreender valores, representações e peculiaridades de um grupo ou indivíduo, a pesquisa quantitativa se torna insuficiente. Além disso, Bernd (2003, p.19), ao comentar sobre o trabalho de Paul Ricoeur, mostra que a identidade não possui outra forma de ser investigada além da narrativa, isto porque, "definir-se é, em última análise, narrar". Essa autora coloca que, para Ricoeur, somente através das histórias que as pessoas ou grupos narram sobre si mesmas, é possível extrair a essência de suas vidas, vislumbrando que significado elas atribuem ao contexto em que estão inseridas.

Nessa mesma linha, foi utilizada a entrevista de história de vida, com o intuito de verificar as mudanças ocorridas na identidade dos sujeitos, a partir dos vários momentos e das várias influências que esses pequenos produtores tiveram durante sua vida no campo e, principalmente, as influências recentes com a implantação do programa Arenito Nova Fronteira na região. Essa modalidade de entrevista permite, de acordo com May (2004), que os sujeitos "naveguem" por significados e ideias com que estejam familiarizados e também oferece um entendimento do ponto de vista dos sujeitos. Para Fontana e Frey (2000), esse tipo de entrevista procura revelar as lutas, sucessos e fracassos das pessoas, possibilitando ao pesquisador observar as variações quanto às ideias e às perspectivas dos entrevistados.

A escolha dos pequenos produtores entrevistados foi conduzida a partir da ideia de Taylor e Bogdan (1998), ao relatarem que a pesquisa qualitativa exige flexibilidade no design da pesquisa. Para esses autores, não é preciso o pesquisador ter, ao certo, o número de informantes, nem é preciso especificá-los anteriormente; basta ter uma ideia geral de quem serão seus possíveis entrevistados, desenvolvida a partir de uma delimitação teórica.

Nesse contexto, foram delimitados, qualitativamente, os sujeitos da pesquisa como pequenos produtores de agricultura familiar, em que o trabalho na propriedade é exercido basicamente pelos membros da família (WANDERLEY, 2001). Além disso, quantitativamente, foi delimitada a característica de sua propriedade (pequena) pela quantidade de terras, a partir de dados extraídos do Instituto Nacional de Reforma Agrária (Incra), que estipula que a pequena propriedade é aquela que possui entre um e quatro módulos fiscais (CARDIM et al, 2005). A quantidade de hectares dos módulos fiscais para a região de Umuarama (PR), de acordo com dados do Conselho Regional de Engenharia, Arquitetura e Agronomia do Estado do Paraná são 20ha (CREA, 2003). Portanto, as propriedades dos sujeitos de pesquisa entrevistados medem entre 20ha e 80ha.

Desse modo, a partir de um relatório cadastral fornecido pela Prefeitura Municipal de Umuarama constando a relação de produtores rurais inscritos no Programa de Arrendamento de Terras (Pater), pôde-se ter acesso aos produtores dessa região para as entrevistas. $\mathrm{O}$ documento apresentava um total de 17 produtores rurais, dos quais dois são grandes produtores, sete são médios e oito são pequenos produtores. No caso, foi possível realizar entrevistas com cinco pequenos produtores rurais.

Feitas as entrevistas propriamente ditas, os dados foram interpretados através da análise de discurso. Esta nos possibilita entender o corpus da entrevista num contexto de produção social dos sentidos, o que não seria possível, por exemplo - como mostra Godoi (2005) -, na análise de conteúdo. Na visão dessa autora, a análise de conteúdo trabalha com um universo mais quantitativo, numa perspectiva informacional, colocando o 
discurso com um conjunto de referências lexométricas, reduzindo o fenômeno da linguagem a categorias simplificadas.

Na perspectiva aqui trabalhada, o discurso passa a ser visto como construções ideológicas e sociais contidas no texto (como materialização da fala), o que possibilita visualizar, no corpus de entrevistas, a produção de sentidos. Essa perspectiva referente ao discurso tem como foco principal o processo de construção social da realidade (BERGER; LUCKMANN, 1995), pois a produção dos sentidos ocorre num contexto histórico-social, que visa à existência de peculiaridades individuais (história), assim como estão atreladas a uma visão compartilhada (social). Assim, para Orlandi (2003), o termo discurso, etimologicamente, tem a ideia de curso, percurso e movimento, o que implica a análise de discurso um trabalho simbólico de construção e compreensão do sentido expresso pelo texto. Feito esse percurso metodológico, o passo seguinte é observar as mudanças na identidade do pequeno produtor da região de Umuarama antes e depois da implantação do programa Arenito Nova Fronteira.

\section{A identidade do pequeno produtor rural antes do Arenito Nova Fronteira}

Para iniciar esta descrição, há que se dizer que não há como negar que a história de vida dos pequenos produtores entrevistados se confunde muito com a história do desenvolvimento da região, desbravada durante a década de 1950, com a derrubada e o corte da mata para a implantação da cultura do café. Nas discussões técnicas sobre a região, viu-se que o solo é predominantemente arenoso, mas que nem sempre ele foi tão improdutivo assim. No início, houve um alto nível de fertilidade, logo após a derrubada das matas, proveniente da matéria orgânica gerada, o que propiciou o desenvolvimento da cultura do café, a qual durante anos se manteve produtiva e lucrativa na região. Mais tarde, em meados da década de 1980, com a perda da fertilidade natural do solo, a cafeicultura entrou em declínio, sendo substituída pela criação extensiva de boi, principalmente, a bovinocultura de corte (MAURINA et al, 1998). Essa discussão perpassa, de maneira particular, o relato dos pequenos produtores:

Desde moleque, a gente trabalha na roça. Aqui, foi em 1964, que eu adquiri as terras. Nessa época eu plantei café. Agora é que está tudo no pasto, porque a lavoura não dá para mexer, né? Não compensa. Aqui era tudo café. Aí, o pessoal foi vendendo, porque o café arruinou de preço, né? E o povo não aguentava mexer mais. [...] Até 1985, a faixa de café era boa... foi bom!....Melhor de todos foi em 1985. Aí, de 1986 para cá, caiu que não deu para fazer quase nada. A gente faz mais ou menos para comer. (JOAQUIM)

A gente mexia com café, moramos sete anos no Mato Grosso, mexendo com café. Fomos para tentar melhorar a situação, na época que o café estava muito bom. Lá não tinha geada. Aí, achamos que o café ia produzir mais e ia dar mais renda. Mas engano do pobre; lá também você tinha que pagar tudo muito mais caro. [...] Aí, não deu nada [risos]. Aí, viemos para cá, compramos uma chácara aqui em Altônia [município perto de Umuarama], mexemos com café também. Um ano pega geada, no outro ano dá seca; aí fomos indo. [...] Aí acabamos mudando para cá [Serra, distrito de Umuarama], na esperança de que morar perto da cidade maior era melhor, mas é a mesma coisa. (AVELINO)

Eu comprei mata. Aqui era tudo mata. Em 1960, aqui era tudo mata. [...] Então, minha vida foi assim, a gente veio para cá, derrubei mata, plantei café. As minhas crianças eram todas pequenas; o mais velho tinha oito anos, e eu entrei formando, derrubei mata, plantei café, e até o café formar, a gente plantava soja, milho, arroz, feijão. Criava-se porco. Eu tinha duas vaquinhas de leite, né? Para criar a família. [...] Então, eu fiquei tocando o café com minha família até 1992, por aí. Eu tocava café. Depois, o café foi acabando e ficou aí uns cinco mil pés. [...] Conforme o café ia morrendo, com a nematoide, porque aqui tinha nematoide. Não acabou tudo de uma vez; levou uns 10 anos para acabar tudo. Conforme o café ia morrendo com a nematoide, eu ia plantando o pasto. Então, eu aumentava o pasto e diminuía o café. (SEBASTIÃO)

Alguns pontos são interessantes para entender o processo de construção da identidade dos pequenos produtores nesses relatos. Primeiro que, diferente do que está expresso no discurso tecnológico sobre a mudança de cultura 
na região, cada um dos pequenos produtores entrevistados vivenciou essa mudança de forma diferente, alguns, relacionando-a à falta de mercado para o café; outros, relacionando-a à doença gerada na lavoura de café ou, ainda, a problemas climáticos que interferiram na produção e na produtividade do café. Além desse fato, algo interessante é possível de ser extraído desses relatos, quando observada a reação dos pequenos produtores ao comentarem sobre essa parte de suas histórias de vida. Apesar da mudança - de café para gado -, o que exige transformações no processo de trabalho, de utilização de tecnologias, esses pequenos produtores veem esse processo como algo que eles próprios construíram. Isto é, a história é vista e relatada por eles como algo que possibilitou, e ainda possibilita, dizer o que eles são, dizer aquilo que os caracterizam e até informar ao outro dos atributos que os qualificam.

Além disso, o relato dos entrevistados mostra certa linearidade, apesar das mudanças ocorridas;onde não existe nostalgia expressa, tanto na fala quanto nos gestos, quando eles discorrem sobre a mudança do cultivo do café para a pecuária extensiva (que são diferentes entre si). O que se percebe é que a mudança não veio a conduzir um processo de desconstrução da identidade construída durante a época de dedicação ao café, mas que essa mudança possibilitou agregar maior atributo à identidade que já vinha sendo construída.

Essa discussão se aproxima do que defende Erikson (1976), ao dizer que a crise de identidade, que estabelece um processo de desconstrução da identidade existente, não altera todo seu conteúdo, mas, sim, alguns atributos. Se, num primeiro momento o sujeito sente esse processo como negativo (devido à mudança de alguns atributos), num segundo momento, é esse processo que permite que o sujeito desenvolva novos atributos que o possibilitem acompanhar as mudanças. Tempos após esse processo é que o sujeito observa aquele estágio como algo pelo qual ele deveria passar para continuar mantendo sua identidade e que, hoje, o qualifica.

Para finalizar essa etapa da análise, outro fator importante a ser observado nessa discussão é que, apesar da mudança no tipo de cultura e de trabalho ser impulsionado pelo ambiente - o que se aproxima da discussão dos "mecanismos de desencaixe" exposta por Giddens $(1991,2002)$ e Domingues $(2001)$-, os pequenos produtores veem esse processo como mudança necessária para continuarem sobrevivendo e mantendo sua identidade. Não aflora aí uma identidade de resistência, como expõe Castells (1999), pelo fato de que persistir na produção e no trabalho com o café não levaria os pequenos produtores a uma solução de seus problemas. Se essa configuração vai ser alterada com a implantação do programa Arenito Nova Fronteira, verificar-se-á na próxima seção.

\section{Arenito Nova Fronteira e a identidade do pequeno produtor rural}

Antes de iniciar esta nova etapa de análise, faz-se necessária uma breve apresentação do contexto do programa Arenito Nova Fronteira. Embora tenha sido oficialmente considerado um programa governamental em setembro de 2001, suas ações no noroeste do Paraná datam de 1997, tendo nascido das pesquisas conduzidas pelo Instituto Agronômico do Paraná (Iapar) sobre cultivares adaptadas aos solos arenosos, principalmente, a soja.

Desde o final da década de 1980, com a queda do setor cafeeiro, a economia agrária da região se assentava na bovinocultura extensiva, devido à pouca produtividade do solo, o que ocasionou, nos anos subsequientes, a sua compactação e vários focos de erosão. Esse quadro causou uma queda acentuada na economia da região, além de colocar o solo, em termos de qualidade, numa situação alarmante, fazendo com que a prefeitura de Umuarama tentasse reverter esse processo. O prefeito, através do Programa de Arrendamento de Terras (Pater), passou a estimular o processo de arrendamento de terras na região, através de incentivos à migração de produtores capacitados a lidar com o plantio da soja, principal cultivar disseminada no Paraná. Esse processo não teve a intenção de substituir a bovinocultura pelo plantio de soja, mas possibilitar uma melhoria na qualidade do solo e a retomada da produtividade da bovinocultura na região, com o rodízio entre culturas e pastagem (MAURINA et al, 1998).

Com a execução do programa, muita coisa mudou na região: desde a vinda de novas pessoas (arrendatários) e cooperativas, até mudanças na paisagem rural - que, de pasto, passou à plantação de soja. Com isso, a dinâmica dos negócios e das relações também se transformou. Desvelar como isso influenciou a identidade dos pequenos produtores rurais é o que segue descrito a seguir. 
As mudanças ocorridas na região de Umuarama, quando observadas pela ótica do desenvolvimento tecnológico, fizeram com que, no dias atuais, fossem acentuadas as diferenças entre os pequenos e grandes produtores. Com a melhoria da situação econômica da região, após a implantação do programa, houve a difusão de tecnologias modernas que foram sendo absorvidas pelos grandes produtores - impulsionando assim o surgimento de várias casas agropecuárias e empresas de tecnologias rurais. Se, no início de alteração do panorama, as tecnologias adotadas por pequenos, médios e grandes produtores eram semelhantes, com o desenvolvimento da região, a grande propriedade começou - devido à quantidade de recursos - a se apropriar de tecnologias cada vez mais modernas, restando aos pequenos produtores - com capacidade restrita de recursos - continuarem trabalhando com as mesmas tecnologias de antes. É o que revelam os seguintes relatos:

Bom, eu vendo o bezerro. Eu crio, desmamo e vendo. Eu não deixo engordar porque... A gente é fraco, né? [risos] e o boi demora muito. Aí, eu vendo os bezerros e compro bezerros, porque o bezerro sai primeiro, né? O boi tem que ser mais pesado, né? Não sei se você entende disso, mas o boi tem que ter 16 arrobas acima, e o bezerro, com 10 arrobas já vende. Então, com dois anos, dois anos e meio, já está vendendo, né? E o boi vai três, quatro anos para pegar o peso. Então, é mais demorado, né? (JOAQUIM)

Eu não engordo não, só crio a bezerrada e vendo. A vaca vai ficando velha, eu descarto e deixo a novilha e vou lutando assim. Não é inseminação, eu tenho touro. (SEBASTIÃO)

Eu trabalho com o gado no pasto. [...] O certo era a gente adubar, né? Mas a renda não está dando para você adubar; aí, eu tenho plantado bastante cana e napie para ajudar o gado, porque só no pasto não dá, né? Não mantém o gado. (PEDRO)

Esses relatos mostram que, diferente da grande propriedade - onde o trabalho é executado através do processo de engorda do gado, de inseminação artificial ou até de confinamento na engorda do boi -, esses pequenos produtores ainda se encontram (no sentido darwinista de desenvolvimento social) num patamar de atraso, utilizando tecnologias que há anos foram utilizadas pelos grandes produtores, mas que hoje não fazem parte de seu processo produtivo. Essas tecnologias perderam o valor para os grandes produtores, pois foram sendo corroídas pelo tempo e pelo aprimoramento de novas tecnologias, embora ainda permitam aos pequenos produtores continuarem trabalhando. É isso que Accarini (1987) diz sobre o processo de desenvolvimento rural brasileiro. Isto é, que as tecnologias geradas proporcionam, cada vez mais, o desenvolvimento de algumas categorias de produção (como a grande propriedade), ao mesmo tempo em que invalidam outras (como no caso da pequena propriedade). Isso tem um forte impacto na identidade dos pequenos produtores, mas voltar-se-á a esse assunto mais adiante.

Dando sequiência à discussão da questão tecnológica, a principal cultura impulsionada pelo programa Arenito Nova Fronteira na região, para fazer rodízio com a pastagem, foi a soja. Entretanto, há tempos, quando a soja era cultivada com tecnologias viáveis aos pequenos - exigindo mais utilização do trabalho humano do que do trabalho mecânico -, os pequenos produtores ainda se aventuravam no seu cultivo. Os relatos a seguir mostram como era feito esse plantio:

Aqui não tinha [soja]. Logo no começo, a gente plantava algum pouco para consumo, né? Aquele tempo que não tinha maquinário, né? Era colhido na mão, mas não plantava do jeito que planta hoje não. Depois que inventou esse negócio do programa Arenito... Sei lá como é que é [risos]... Aí, começou a plantar. (JOAQUIM)

Eu mesmo plantei soja, aqui, no meio do café. Eu plantava soja de matraquinha assim, e recolhia com o ferro, cortava com o ferro. Depois, batia numa máquina chamada trilhadeira. Tinha que jogar a soja em cima, para ela bater. Eu colhi 100 sacas de soja cortando com o ferro, o pé, e depois a gente fez um monte, eи e a mulher. A mulher me ajudou, 100 sacas de soja; eu cortei e empilhei, eu e ela. Depois, eи paguei um para bater. (SEBASTIÃO)

Se num passado não muito distante, como mostram esses relatos, os pequenos produtores entrevistados tiveram a possibilidade de cultivar soja, no panorama atual, essa possibilidade é muito menor, pois as tecnologias 
geradas para o processo de trabalho, cultivo e colheita da soja exigem altos investimentos, inviabilizando seu cultivo em pequenas áreas. Isso quer dizer que, a partir do momento em que a soja, mercadologicamente, tornase viável apenas em grandes áreas de terra e com maquinário sofisticado, o próprio programa tirou as possibilidades do pequeno produtor de se ver inserido nele. É nesse cenário que este se vê numa situação de marginalização.

Essa discussão mostra que, ao invés de ocorrer a manutenção da identidade construída pelos pequenos produtores, houve a sua desconstrução. Um dos atributos ligados aos ideais dessa categoria "pequeno produtor" está na comparação com a grande propriedade - moderna, capacitada e bem-sucedida. Claro que o pequeno produtor não estabelece essa comparação em termos de igualdade, mas em termos de algo que Hegel (2002) chamou de "vir-a-ser-de-si-mesmo", ou seja, de um dia esse sujeito vir a ser um pequeno produtor moderno, capacitado e bem-sucedido. Assim, o pequeno produtor não pretende ser o grande produtor, pois ele tem consciência daquilo que é, mas ele traça perspectivas de utilização de uma tecnologia moderna que esteja ligada à sua realidade. Isso é possível observar nos seguintes relatos:

Oh! Aí é difícil, viu? Porque em termos de pequena propriedade, ou se adapta à tecnologia moderna, você passa a produzir bastante em pouca área, ou você pode ir para a cidade. É o que a gente tenta aqui; a gente está mexendo, né? Ou você passa a produzir em pequenas áreas ou vai ter que voltar para a rua. [...] Existe assim, se você mesmo aplicar, como se diz, ir apanhando e tentando. Enxerga do grande e tenta copiar. Se der certo, parabéns para você; se não der certo, perdeu tudo [risos]. Você tem que olhar o do grande e copiar. Se der certo, parabéns para você; se não, você vai para a rua de novo [risos]. (AVELINO)

Eu acho que tem que se buscar uma coisa diferente. Tem que buscar uma coisa nova para fazer a propriedade dar lucro, para a propriedade ter um retorno. Se você ficar com pequenas plantações de cereais na pequena propriedade, não. Para mim, não é uma atividade que dê grandes resultados. [...] Procurar alternativa. Ah, antigamente, a gente via muita produção de café em pequenas propriedades, $e$, hoje, para essa propriedade dar lucro, como eu te falei, a gente tem que buscar alternativas novas. Tem que buscar coisas que deem resultados. (JOSÉ)

Os relatos mostram, mais uma vez, que se um dia as tecnologias utilizadas na região eram semelhantes entre grandes, médios e pequenos produtores, nos dias atuais, essas diferenças se acentuaram e somente a grande propriedade consegue se desenvolver, utilizando tecnologias modernas. Os pequenos produtores até tentam impulsionar em sua propriedade, tecnologias semelhantes às utilizadas pelos grandes, pois sabem que é aquele modelo que conduz ao sucesso no mercado. Nesse cenário, há um profundo processo de desconstrução da identidade do pequeno produtor, pois o desenvolvimento impulsionado pelo programa - apesar de ter conduzido a uma melhoria na economia da região - acentuou mais ainda os problemas enfrentados pelo pequeno produtor.

É isso que possibilita outra perspectiva sobre a implantação do programa Arenito Nova Fronteira, cujo objetivo era desenvolver tanto a grande e a média propriedade rural, quanto a pequena. $\mathrm{O}$ que se percebe, novamente, no discurso dos pequenos produtores é que o programa veio impulsionar, na realidade, o desenvolvimento da grande propriedade:

Mas esse programa é mais para fazenda, incentivando o plantio de soja. Eles falaram que o programa deu certo, só que o pessoal está [risos]... Tudo afundou... A maioria pegava fazenda para arrendar para pagar em soja... Acho que são 30 sacas, né? Por alqueire. Então... Na primeira vez, acho que colheu um bom tanto; depois, no segundo ano, caiu que não deu nem para pagar a renda. (JOAQUIM)

[...] minha área é pequena. Geralmente, esse pessoal quer uma área maior. Por exemplo, se eles tivessem pegado a divisa aqui, se eu quisesse arrendar um pedaço, talvez eles pegariam, mas como é longe, aí para eles pegarem aí, negócio de 5 ou 10 alqueires, acho que não compensa deslocar o maquinário, né? [...] Então, para área pequena, todas as coisas são difíceis, porque uma área grande para você fazer um financiamento também sai mais dinheiro, é mais fácil para você trabalhar. (PEDRO) 
[...] para o pequeno agricultor continua a mesma coisa, porque esse Arenito Nova Fronteira foi a implantação do plantio de soja na região, e quem plantou soja aqui foi só o grande produtor. Isso porque eles têm mais terra para trabalhar, e o pequeno produtor, para arrumar terra para plantar soja, eu acho que é inviável. (JOSÉ)

Tal situação gera certa nostalgia nesses pequenos produtores. De acordo com a discussão conduzida por Erikson (1976), o sentimento positivo de uma identidade construída daria ao indivíduo certo orgulho daquilo que ele faz, daquilo que é possível ser construído. Porém, na situação atual - com a pequena propriedade marginalizada desse processo particular de desenvolvimento -, o que se percebe é um sentimento negativo, fruto de uma identidade desconstruída, pois já não existem mais tantos atributos qualificadores. É nesse cenário, então, que se observa certa melancolia na fala dos pequenos produtores, os quais descaracterizam a época atual e se vinculam a uma época em que os atributos ligados a sua identidade lhes possibilitavam maior orgulho, como se pode observar nestes relatos:

Eu acho que antigamente era mais fácil a vida. De uns tempos para cá, eu não sei se é o custo de vida ou o que é, ou se a produção caiu, né? Está difícil hoje no sítio. [...] O leite também. Se você não tratar o gado, não produz muito leite, e o leite está muito baixo. No ano passado, eu vendi leite, nessa época, a 54 centavos, e esse ano, está 36 centavos. E as coisas da cidade que você vai comprar só sobem, né? Combustível mesmo, quantas vezes não subiu? Energia... O gado mesmo, está difícil de vender. Você vai vender um bezerro de leite, está ruim no comércio. (PEDRO)

Eu acho que não, não tem muita melhoria, não. No geral, quem na época tinha uma atividade, continua na mesma atividade, não melhorou em nada. Se tivesse melhorado alguma coisa de lá para cá, a gente veria as pessoas aqui na região em melhor situação. O que eu não vejo; pelo contrário, piorou bastante. Sabe o que eu penso disso? Você pega, por exemplo, esses programas governamentais de acabar com a fome, distribuindo um salário de miséria, em vez de falar "vamos ensinar você", "vamos dar condição para você se manter"; mas, não, dão um salariozinho de miséria. O pior disso tudo, é que as pessoas ainda não têm consciência, ganham uma miséria e não estão nem aí. (JOSÉ)

É, mas foi muito pouco o que ele [o programa] fez, né? Se você pensar o que era para produzir na região, hoje, não consegue produzir nada. $O$ ano passado foi uma época de produzir mandioca. Esse ano, ninguém vai plantar, porque não compensa. Então, hoje está difícil, né? Como se fazer, eu não sei! [risos]. (AVELINO)

Diante dessa visão dos pequenos produtores sobre a situação de sua categoria na região de Umuarama e de toda a discussão gerada até esse ponto, seria interessante centralizar os indícios levantados até aqui, mais explicitamente, sobre as discussões quanto à identidade. Nesse ponto, é visível que o programa Arenito Nova Fronteira instaurou o que Giddens (1991, 2002) e Domingues (2001) chamam de "mecanismo de desencaixe", pois conduziu a uma mudança acentuada no panorama da região.

Vale salientar que o programa não tinha a intenção de substituir a bovinocultura pelo plantio da soja, mas, sim, fazer o rodízio entre pastagem e plantio de grãos. Entretanto, observando a viabilidade instaurada pela soja na região, muitos grandes produtores realizaram essa substituição e passaram a cultivá-la. Nesse cenário, a bovinocultura perdeu o valor e a importância que tinha, mas essa foi a opção que restou aos pequenos produtores.

Entretanto, isso não significa que os pequenos produtores perderam o valor e o significado daquilo que fazem, mas aquilo que eles fazem perdeu valor e o significado para a própria sociedade. Erikson (1976) diz que há a necessidade de um reconhecimento mútuo no processo de construção da identidade; se não há reconhecimento social por aquilo que o indivíduo realiza, então, é possível detectar aí a crise de identidade. 


\section{Conclusão}

Diante das discussões desenvolvidas nesta investigação, vale retomar o objetivo proposto neste artigo, que é compreender a influência de um programa governamental de desenvolvimento tecnológico, denominado Arenito Nova Fronteira, na identidade do pequeno produtor inserido no município de Umuarama (PR) onde se verificou esse processo de desenvolvimento. Em termos da pesquisa em si, o que foi possível observar das narrativas dos pequenos produtores é que a implantação do programa Arenito Nova Fronteira na referida região contribuiu, acentuadamente, para um processo de desencaixe e desconstrução de sua identidade. Desencaixe porque, após a derrocada do café, a região do noroeste do Paraná passou a ser uma região predominantemente voltada para a bovinocultura de corte e de leite. Com a implantação do cultivo de grãos - que demanda tecnologias avançadas - a configuração da região se alterou e a bovinocultura perdeu seu valor econômicosocial.

Retomando algumas considerações sobre a identidade, no sentido de que há uma interseção entre o mundo subjetivo e o mundo objetivo, a constituição do mundo subjetivo é realizada a partir da internalização dos atributos do mundo objetivo. Quando este passa por alterações é necessário que ocorram mudanças também em nível subjetivo. Se as mudanças que ocorreram na região "desvalorizaram" ou inviabilizaram economicamente a bovinocultura, seria necessário que também a pequena unidade rural tivesse oportunidades de se alterar, com a possibilidade de participação nesse processo de mudança. Só assim ocorreria o ciclo de desconstrução e reconstrução de novos atributos na identidade do pequeno produtor. Da maneira como foi conduzido o processo de desenvolvimento, entretanto, nenhuma oportunidade foi aberta aos pequenos produtores. Aqui, os pequenos produtores não estão submetidos a uma realidade reificante, pois a implantação de grãos na região nem mesmo chegou a ser impulsionada nessa modalidade de produção. Muito pelo contrário, como foi possível observar nas discussões sobre o desenvolvimento tecnológico na agricultura, a pequena propriedade continuou à margem do processo, sem possibilidades de participação.

Esse é um fato interessante e problemático, pois quanto maior for o desenvolvimento tecnológico de alguns setores da agricultura, menor a possibilidade de muitos produtores participarem do processo, o que implica exclusão, além de desqualificar e desvalorizar sua modalidade de trabalho. Essas considerações giram, implicitamente, em torno do estudo de Heidegger (1971) e de sua crítica ao "universo da técnica", por este reduzir todo qualificativo do ser humano aos atributos técnicos, desconsiderando justamente os atributos humanos. Isso faz com que o ser "pequeno produtor" esteja em sintonia com aquilo que o qualifica, o universo da técnica; universo esse que vai definir o seu valor e reconhecimento social. Infelizmente, as ações do programa Arenito Nova Fronteira, nem mesmo no que tange ao universo da técnica, possibilitou essa valorização e esse reconhecimento, colocando os sujeitos pequenos produtores num processo de desconstrução de sua identidade, sem possibilitar-lhes reconstruí-la. Esse fato fica evidente na fala desses pequenos produtores, quando explicam sua situação e o insucesso que o programa representou para eles.

Por esse motivo, estando a história da região atrelada à história dos pequenos produtores, é possível detectar que - antes da implantação do programa - os pequenos produtores tiveram a possibilidade de participar das mudanças ali ocorridas. Após a implantação do Arenito Nova Fronteira, os pequenos produtores não tiveram a possibilidade de se sentirem protagonistas das novas transformações, o que despertou neles a nostalgia revelada em suas falas.

Vale salientar que, apesar de toda a discussão e crítica sobre os modos de intervenção e de desenvolvimento tecnológico na agricultura, ainda hoje, esse processo vem sendo conduzido de forma semelhante ao que se efetivou nas décadas de 1960 e 1970, numa perspectiva muito semelhante ao que Carvalho (1991) chamou de "modelo concentrado", durante o surgimento da Embrapa. Após anos de discussão e de insistência de vários estudiosos sobre como esses processos de desenvolvimento deveriam ser conduzidos, o que se vê, particularmente no contexto do programa Arenito Nova Fronteira, é que pouca coisa mudou.

Acredita-se que essa seja a contribuição deste artigo: possibilitar a visualização do ponto de vista daqueles que sofrem o impacto de mudanças desse porte e refletir sobre as diversas maneiras de se conduzir esse tipo de programa governamental de desenvolvimento tecnológico na agricultura, de forma que levem em consideração 
a capacidade e a potencialidade dos sujeitos. Somente assim, será possível dar-lhes uma chance para a construção e a reconstrução de suas identidades, e não somente desconstruí-las, como se viu nos depoimentos de Joaquim, Pedro, Avelino, Sebastião e José. 


\section{Referências}

ACCARINI, José Honório. Economia rural e desenvolvimento: reflexões sobre o caso brasileiro. Petrópolis, RJ: Vozes, 1987.

ALENCAR, Edgard. Associativismo rural e estratégia e intervenção. Lavras: UFLA/DAE, 1997 (Roteiro para discussão).

ALVES, Eliseu. Pobreza rural no Brasil: desafios da extensão e da pesquisa. Brasilia: CODEVASF, 1988.

AMMANN, Safira Bezerra. Ideologia do desenvolvimento de comunidades no Brasil. São Paulo: Cortez, 1980.

BERGER, Peter L.; LUCKMANN, Thomas. A construção social da realidade. 15.ed. Tradução: Floriano de Souza Fernandes. Petrópolis: Vozes, 1985.

BERND, Zilá. Literatura e identidade nacional. 2.ed. Porto Alegre: UFRGS, 2003.

CARDIM, Sílvia Elisabeth de C. S.; VIEIRA, Paulo de Tarso L.; VIÉGAS, José Leopoldo R. Análise da estrutura fundiária brasileira. Net. Brasília, DF: Instituto Nacional de Colonização e Reforma Agrária (Incra). jan. 2005. Disponível em: <www.url:http://www.incra.gov.br/_htm/serveinf/_htm/pubs/pubs.htm>. Acesso em: 17 ago. 2005.

CARVALHO, João Carlos M. 0 desenvolvimento da agropecuária brasileira. Brasilia, DF: Embrapa, 1992. 171p.

CASTELLS, Manuel. 0 poder da identidade. In: CASTELLS, Manuel. A era da informação: economia, sociedade e cultura. Tradução: Klauss Brandini Gerhardt. 2.ed. São Paulo: Paz e Terra, 1999. v.Il.

CASTRO, Ana Célia et al. Evolução recente e situação atual da agricultura brasileira: sintese das transformações. Brasilia, DF: Binagri, 1979.

CREA - Conselho Regional de Engenharia e Agronomia do Paraná. Manual de orientação da câmara especializada de agronomia. Curitiba: Crea-PR, 2003.

ERIKSON, Erik H. Identidade: juventude e crise. Tradução: Álvaro Cabral. 2.ed. Rio de Janeiro: Zahar Editores, 1976.

DOMINGUES, José Maurício. Cidadania, direitos e modernidade. In: SOUZA, Jessé (Org.). Democracia hoje: novos desafios para a teoria democrática contemporânea. Brasilia, DF: Universidade de Brasilia, 2001.

FONTANA, Andrea; FREY, James H. The interview: from structured questions to negotiated text. In: DENZIN, Norman K.; LINCOLN, Yvonna S. (Ed.). The handbook of qualitative research. $2^{\text {nd }}$ ed. Thousand Oaks, CA: Sage Publications, 2000.

FREIRE, Paulo. Extensão ou comunicação? Tradução: Rosisca Darcy de Oliveira. Rio de Janeiro: Paz e Terra, 1977.

FREUD, Sigmund. Formulações sobre os dois princípios do funcionamento mental. In: Edição standard brasileira das obras psicológicas completas de Sigmund Freud. Rio de Janeiro: Editora Imago, 1974. v.XIV.

Além do principio do prazer. In: Edição standard brasileira das obras psicológicas completas de Sigmund Freud. Rio de Janeiro: Editora Imago, 1975. v.XVIII. 0 mal-estar na civilização. In: Edição standard brasileira das obras psicológicas completas de Sigmund Freud. Rio de Janeiro: Editora Imago, 1976a. v.XXI.

0 ego e o id. In: Edição standard brasileira das obras psicológicas completas de Sigmund Freud. Rio de Janeiro: Editora Imago, 1976b. v.XIX.

FURTADO, Celso. Formação econômica do Brasil. Rio de Janeiro: Fundação Cultura, 1963.

GIDDENS, Anthony. As conseqüências da modernidade. Tradução: Raul Fikel. São Paulo: Unesp, 1991.

Modernidade e identidade. Tradução: Plínio Dentzien. Rio de Janeiro: Jorge Zahar, 2002.

GODOI, Christiane Kleinübing. Análise do discurso na perspectiva da interpretação social dos discursos: uma possibilidade aberta aos estudos organizacionais. Revista Eletrônica de Gestão Organizacional - Gestão.org, v.3, n.2, p.90-105. maio/jun. 2005.

HABERMAS, Jürgen. 0 discurso filosófico da modernidade. Tradução: Ana Maria Bernardo et al. Lisboa: Dom Quixote, 1990. 
HEGEL, Georg Wilhelm Friedrich. Fenomenologia do espírito. Tradução: Paulo Menezes. 7.ed. rev. Petrópolis, RJ: Vozes, 2002.

HEIDEGGER, Martin. 0 que é isto - a filosofia? Identidade e diferença. Tradução: Ernildo Stein. São Paulo: Duas Cidades, 1971.

ICHIKAWA, Elisa Yoshie. 0 Estado no apoio à pesquisa agrícola: uma visão histórica. Revista de Administração Pública, v.34, n.3, p.89102, maio/jun. 2000.

MARCUSE, Herbert. Razão e revolução: Hegel e o advento da teoria social. Tradução: Marília Barroso. 3.ed. Rio de Janeiro: Paz e Terra, 1978.

MAURINA Antonio C. et al. Arenito Caiuá: integração agricultura e pecuária. Curitiba: Emater, 1998.

MAY, Tim. Pesquisa social: questões, métodos e processos. Tradução: Carlos Alberto Silveira N. Soares. 3.ed. Porto Alegre: Artmed, 2004.

MINAYO, Maria Cecilia de S. 0 desafio do conhecimento: pesquisa qualitativa em saúde. 4.ed. São Paulo: Hucitec-Abrasco, 1996.

ORLANDI, Eni Puccinelli. Análise de discurso: princípios e procedimentos. 5.ed. Campinas, SP: Pontes, 2003.

SOUZA SANTOS, Boaventura. Pela mão de Alice: o social e o político na pós-modernidade. São Paulo: Perspectiva, 1991.

TAYLOR, Steven J.; BOGDAN, Robert. Introduction to qualitative research methods: a guidebook and resource. $3^{\text {rd }}$ ed. Canada: John Wiley \& Sons Inc., 1998.

TOURAINE, Alain. Crítica da modernidade. Tradução: Elia Ferreira Edel. 3.ed. Petrópolis, RJ: Vozes, 1995.

WANDERLEY, Maria de Nazareth Baudel. Raízes históricas do campesinato brasileiro. In: TEDESCO, João Carlos (Org.). Agricultura familiar: realidades e perspectivas. 3.ed. Passo Fundo: UPF, 2001 